\title{
Rhizoferrin Glycosylation in Rhizopus microsporus
}

\author{
Anton Škríba ${ }^{1}$, Rutuja Hiraji Patil ${ }^{1,2}{ }^{1}$, Petr Hubáček $^{3}$, Radim Dobiáš $^{4}$, Andrea Palyzová ${ }^{1}$, \\ Helena Marešová ${ }^{1}$, Tomáš Pluháček ${ }^{1,2}$ and Vladimír Havlíček ${ }^{1,2, *(\mathbb{D})}$ \\ 1 Institute of Microbiology of the Czech Academy of Sciences, Vídeňská 1083, 14220 Prague, Czech Republic; \\ anton.skriba@biomed.cas.cz (A.Š.); rutuja.patil@biomed.cas.cz (R.H.P.); palyzova@biomed.cas.cz (A.P.); \\ maresova@biomed.cas.cz (H.M.); tomas.pluhacek@biomed.cas.cz (T.P.) \\ 2 Department of Analytical Chemistry, Faculty of Science, Palacký University, 77146 Olomouc, Czech Republic \\ 3 Department of Medical Microbiology, 2nd Faculty of Medicine, Charles University and Motol University \\ Hospital, 15006 Prague, Czech Republic; petr.hubacek@fnmotol.cz \\ 4 Public Health Institute in Ostrava, 70200 Ostrava, Czech Republic; radim.dobias@zuova.cz \\ * Correspondence: vlhavlic@biomed.cas.cz
}

Received: 18 May 2020; Accepted: 16 June 2020; Published: 18 June 2020

\begin{abstract}
Rhizopus spp. are the most common etiological agents of mucormycosis, causing over $90 \%$ mortality in disseminated infections. The diagnosis relies on histopathology, culture, and/or polymerase chain reaction. For the first time, the glycosylation of rhizoferrin (RHF) was described in a Rhizopus microsporus clinical isolate by liquid chromatography and accurate tandem mass spectrometry. The fermentation broth lyophilizate contained $345.3 \pm 13.5,1.2 \pm 0.03$, and $0.03 \pm 0.002 \mathrm{mg} / \mathrm{g}$ of RHF, imido-RHF, and bis-imido-RHF, respectively. Despite a considerable RHF secretion rate, we did not obtain conclusive RHF detection from a patient with disseminated mucormycosis caused by the same R. microsporus strain. We hypothesize that parallel antimycotic therapy, RHF biotransformation, and metabolism compromised the analysis. On the other hand, the full profile of posaconazole metabolites was retrieved by our in house software CycloBranch.
\end{abstract}

Keywords: Rhizopus microsporus; glycoside; rhizoferrin; metabolite; siderophore; mass spectrometry; liquid chromatography; human isolate; posaconazole metabolism

\section{Introduction}

Mucorales are mainly saprophytes that are commonly found in soil and decomposing material. Nevertheless, some of these fungi have been used for centuries in food manufacturing for cheese ripening or Asian fermented food production. The metabolome of mucoromycetes is poorly studied, and only a limited number of reports have appeared so far [1,2]. Fifteen different sterols were detected in clinically relevant Mucorales species in a targeted metabolomics fashion, after derivatization, by gas chromatography-mass spectrometry [3]. In an older report, trisporic acids were described as C-18 terpenoid pheromone compounds responsible for sexual differentiation in Mucorales [4]. Trisporic acid E, along with 12 other apocarotenoids, was identified in the culture media of Phycomyces blakesleeanus. Cytotoxic 3-nitropropionic acid was detected in the culture extract of Mucor circinelloides [5].

Certain Rhizopus microsporus strains have erroneously been reported to produce either pharmaceutically active rhizoxins or highly toxic rhizonins [6]. In a consequent study, other authors demonstrated that these metabolites are not secreted by the fungus but are produced by Bulkholderia symbionts that reside within the fungal cytosol [7]. As R. microsporus has been used for fermented soy production, one cannot exclude a link between intracellular bacteria producing toxins and their harmful effects on humans. The small molecule metabolome of selected Mucorales species is summarized in Table 1. 
Table 1. Small molecules described in Mucorales. If not stated otherwise, the abbreviated genera M., R., L., and C. stand for Mucor, Rhizopus, Lichtheimia, and Cunninghamella, respectively. M: monoisotopic molecular weight; RHF: rhizoferrin; ${ }^{1}$ Reported in Phycomyces blakesleeanus; ${ }^{2}$ Described in Blakeslea trispora; ${ }^{3}$ Known also as glomuferrin [8]; ${ }^{4}$ Known as staphyloferrin; ${ }^{*}$ This work.

\begin{tabular}{|c|c|c|c|c|c|c|c|c|c|c|c|c|}
\hline M & Metabolite & Formula & R. microsporus & $\begin{array}{c}M . \\
\text { irregularis }\end{array}$ & $\begin{array}{c}R . \\
\text { delemar }\end{array}$ & $\begin{array}{c}L . \\
\text { corymbifera }\end{array}$ & $\begin{array}{c}\text { Rhizobium } \\
\text { meliloti }\end{array}$ & $\begin{array}{c}C . \\
\text { echinulata }\end{array}$ & $\begin{array}{c}C . \\
\text { elegans }\end{array}$ & $\begin{array}{c}\text { Rhizomucor } \\
\text { pusillus }\end{array}$ & $\begin{array}{c}M . \\
\text { circinelloides }\end{array}$ & References \\
\hline 119.0219 & 3-Nitropropionic acid & $\mathrm{C}_{3} \mathrm{H}_{5} \mathrm{NO}_{4}$ & & & & & & & & & & [5] \\
\hline 262.1165 & $\begin{array}{c}\text { RHF citryl } \\
\text { intermediate }\end{array}$ & $\mathrm{C}_{10} \mathrm{H}_{18} \mathrm{~N}_{2} \mathrm{O}_{6}$ & & & & & & & & & & [9] \\
\hline 289.1804 & Trisporic acid $\mathrm{E}^{1}$ & $\mathrm{C}_{18} \mathrm{H}_{25} \mathrm{O}_{3}$ & & & & & & & & & & [10] \\
\hline 290.1882 & Trisporic acid A & $\mathrm{C}_{18} \mathrm{H}_{26} \mathrm{O}_{3}$ & & & & & & & & & & [11] \\
\hline 304.1675 & Trisporic acid B & $\mathrm{C}_{18} \mathrm{H}_{24} \mathrm{O}_{4}$ & & & & & & & & & & [11] \\
\hline 306.1831 & Trisporic acid C & $\mathrm{C}_{18} \mathrm{H}_{26} \mathrm{O}_{4}$ & & & & & & & & & & [11] \\
\hline 320.1624 & Trisporic acid $\mathrm{D}^{2}$ & $\mathrm{C}_{18} \mathrm{H}_{24} \mathrm{O}_{5}$ & & & & & & & & & & [12] \\
\hline 376.1720 & Rhizobactin & $\mathrm{C}_{15} \mathrm{H}_{26} \mathrm{~N}_{3} \mathrm{O}_{8}$ & & & & & & & & & & [13] \\
\hline 384.1169 & Desoxy-bis-imido-RHF & $\mathrm{C}_{16} \mathrm{H}_{20} \mathrm{~N}_{2} \mathrm{O}_{9}$ & & & & & & & & & & [14] \\
\hline 400.1118 & Bis-imido-RHF ${ }^{3}$ & $\mathrm{C}_{16} \mathrm{H}_{20} \mathrm{~N}_{2} \mathrm{O}_{10}$ & & & & & & & & & & {$[14,15]$} \\
\hline 404.1431 & Di-desoxy-RHF & $\mathrm{C}_{16} \mathrm{H}_{24} \mathrm{~N}_{2} \mathrm{O}_{10}$ & & & & & & & & & & [14] \\
\hline 418.1224 & Imido-RHF & $\mathrm{C}_{16} \mathrm{H}_{22} \mathrm{~N}_{2} \mathrm{O}_{11}$ & & & & & & & & & & {$[14,15]$} \\
\hline 420.1380 & Mono-desoxy-RHF & $\mathrm{C}_{16} \mathrm{H}_{24} \mathrm{~N}_{2} \mathrm{O}_{11}$ & & & & & & & & & & [14] \\
\hline 422.1173 & Nor-RHF ${ }^{4}$ & $\mathrm{C}_{15} \mathrm{H}_{22} \mathrm{~N}_{2} \mathrm{O}_{12}$ & & & & & & & & & & [14] \\
\hline 432.1744 & Di-methyl-di-desoxy-RHF & $\mathrm{C}_{18} \mathrm{H}_{28} \mathrm{~N}_{2} \mathrm{O}_{10}$ & & & & & & & & & & [14] \\
\hline 434.1537 & Methyl-desoxy-RHF & $\mathrm{C}_{17} \mathrm{H}_{26} \mathrm{~N}_{2} \mathrm{O}_{11}$ & & & & & & & & & & [14] \\
\hline 435.2404 & Rhizovarin F & $\mathrm{C}_{27} \mathrm{H}_{33} \mathrm{NO}_{4}$ & & & & & & & & & & [16] \\
\hline 436.1329 & Rhizoferrin (RHF) & $\mathrm{C}_{16} \mathrm{H}_{24} \mathrm{~N}_{2} \mathrm{O}_{12}$ & & & & & & & & & & {$[9,14]$} \\
\hline 450.1122 & 2-Oxo-RHF & $\mathrm{C}_{16} \mathrm{H}_{22} \mathrm{~N}_{2} \mathrm{O}_{13}$ & & & & & & & & & & [14] \\
\hline 450.1486 & Homo-RHF & $\mathrm{C}_{17} \mathrm{H}_{26} \mathrm{~N}_{2} \mathrm{O}_{12}$ & & & & & & & & & & [14] \\
\hline 452.1278 & 2-Oxa-homo-RHF & $\mathrm{C}_{16} \mathrm{H}_{24} \mathrm{~N}_{2} \mathrm{O}_{13}$ & & & & & & & & & & [14] \\
\hline 464.1642 & 2-Methyl-homo-RHF & $\mathrm{C}_{18} \mathrm{H}_{28} \mathrm{~N}_{2} \mathrm{O}_{12}$ & & & & & & & & & & [14] \\
\hline 603.3560 & Rhizovarin D & $\mathrm{C}_{37} \mathrm{H}_{49} \mathrm{NO}_{6}$ & & & & & & & & & & [16] \\
\hline 615.3560 & Rhizovarin E & $\mathrm{C}_{38} \mathrm{H}_{49} \mathrm{NO}_{6}$ & & & & & & & & & & [16] \\
\hline 645.3302 & Rhizovarin C & $\mathrm{C}_{38} \mathrm{H}_{47} \mathrm{NO}_{8}$ & & & & & & & & & & [16] \\
\hline 769.2111 & Rhizovarin A & $\mathrm{C}_{37} \mathrm{H}_{44} \mathrm{ClNO}_{8}$ & & & & & & & & & & [16] \\
\hline 783.2268 & Rhizovarin B & $\mathrm{C}_{38} \mathrm{H}_{46} \mathrm{ClNO}_{8}$ & & & & & & & & & & [16] \\
\hline 742.2280 & Di-Hex-imido-RHF & $\mathrm{C}_{28} \mathrm{H}_{42} \mathrm{~N}_{2} \mathrm{O}_{21}$ & & & & & & & & & & * \\
\hline 760.2386 & Di-Hex-RHF & $\mathrm{C}_{28} \mathrm{H}_{44} \mathrm{~N}_{2} \mathrm{O}_{22}$ & & & & & & & & & & * \\
\hline 1084.3442 & Tetra-Hex-RHF & $\mathrm{C}_{40} \mathrm{H}_{64} \mathrm{~N}_{2} \mathrm{O}_{32}$ & & & & & & & & & & * \\
\hline
\end{tabular}


All mucoralean genomes available in 2014 were reported to lack nonribosomal peptide synthetases (NRPSs) [17]. Controversially, more recent work identified polyketide synthase, NRPS, and L-tryptophan dimethylallyl transferase encoding genes in Mucoromycota [2]. Mucorales also synthesize polycarboxylate siderophores, including rhizoferrin (RHF) [18], which have a much weaker binding activity than hydroxamate siderophores but may be important for microbial virulence, as reported, e.g., in Francisella tularensis [19]. Recently, rhizoferrin biosynthetic genes have been identified in the Mucorales species R. delemar [9]. An expressed and purified $72 \mathrm{kDa}$ protein Rfs corresponded to a superfamily of adenylating enzymes, and its sequence was similar to that of a homologous bacterial NRPS-independent siderophore (NIS) protein, SfnaD, that is involved in the biosynthesis of staphyloferrin A in Staphylococcus aureus [20].

Siderophores represent a subset of metallophores, a diverse family of secondary metabolites with numerous biological functions covering resistance to reactive oxygen species, ability to produce sexual spores, and modulation of host functions; these compounds can be both genotoxic and/or cancerostatic [21]. Metallophores are metal-chelating molecules secreted by pathogens to facilitate metal acquisition/passivation, thereby representing a significant group of microbial pleiotropic virulence factors [22]. These molecules have a high secretion rate at the invasive stage of a disease and can be strain specific. They are used as therapeutics [23,24], and have also been defined as critical early markers of fungal infections $[25,26]$. The complex structures of siderophores offer great diagnostic potential in terms of specificity, but variable or mixed moieties confer the final physicochemical properties that affect sample preparation [27]. In contrast to immune host responses to the presence of infections, which are spatiotemporally nonspecific, direct monitoring of microbial siderophores is specific. False positivity is almost excluded, as siderophores are not synthesized by mammalian cells except for small catechols [28,29].

Specifically, for Mucorales, RHF was reported in Syncephalastrum racemosum, Rhizomucor pusillus, Mucor hiemalis [9], a number of arbuscular mycorrhizal fungi [15], and the other Mucorales species listed in Table 1. RHF is also actively secreted by some clinically important bacteria, including Francisella tularensis [19], Ralstonia (Pseudomonas) pickettii [30], and Legionella pneumophila (in [31] referred to as legiobactin). As a xenosiderophore, RHF uptake has been described in Morganella morganii [32] and Mycobacterium smegmatis [33]. Some RHF analogs were prepared by directed fermentation [14].

Importantly, Mucorales genera Rhizopus, Lichtheimia (formerly Absidia), Mucor, Rhizomucor, and Cunninghamella have been isolated in high abundance from patient material. The major obstacle in the management of mucormycosis has been a lack of a noninvasive, rapid, and reliable diagnostic test [34]. Rhizopus spp. are the most common etiological agents of mucormycosis, causing over $90 \%$ mortality in disseminated infections [35]. The high rate could be attributed to late invasive sampling from primarily sterile material and inadequate activity of antifungals applied in prophylaxis [36].

Of note, the bacterial siderophore deferoxamine B (Desferal) can be misappropriated by Mucorales to stimulate their growth in patients with mucormycosis [37]. Furthermore, antibiotic treatment in at-risk patients may eliminate a bacterium that keeps mucormycosis under control. Coculturing R. microsporus and Pseudomonas aeruginosa resulted in the inhibition of spore germination via the secretion of bacterial siderophores [38]. The iron complex in bacterial pyoverdine has a much higher stability constant than that of hydroxamate RHF, indicating a better armament for intramicrobiome combat [39].

Motivated by the lack of a new tool for the noninvasive diagnosis of mucormycosis, we present the metabolome of a R. microsporus patient isolate, which was retrieved in 2019. This in vitro metabolic profile was compared to the urinal profile of the same patient with proven $R$. microsporus invasive infection confirmed by internal transcribed spacer (ITS) sequence-based identification. A new chromatographic method for carboxylate siderophore separation was developed, and the Rhizopus metabolome was probed by our software tool called CycloBranch [40]. 


\section{Materials and Methods}

\subsection{Strain Cultivation, Fungal Extraction, and Metabolite Analysis}

R. microsporus isolate was obtained from the sputum of an immunocompromised patient and grown in iron-depleted mineral medium (residual content $235.5 \mu \mathrm{g}$ of Fe/L) containing $55 \mathrm{mM}$ glucose, $50 \mathrm{mM} \mathrm{NH}_{4} \mathrm{Cl}, 11.2 \mathrm{mM} \mathrm{KH}_{2} \mathrm{PO}_{4}, 7 \mathrm{mM} \mathrm{KCl}, 2.1 \mathrm{mM} \mathrm{MgSO}_{4} \times 7 \mathrm{H}_{2} \mathrm{O}, 68 \mu \mathrm{M} \mathrm{CaCl}_{2} \times 2 \mathrm{H}_{2} \mathrm{O}$, and 20 $\mu \mathrm{M} \mathrm{ZnSO}_{4} \times 7 \mathrm{H}_{2} \mathrm{O}\left(\mathrm{pH}\right.$ 6.5). The medium was inoculated with spore suspension $\left(10^{7}\right.$ spores $\left./ \mathrm{mL}\right)$ and incubated for $48 \mathrm{~h}$ at $30^{\circ} \mathrm{C}$ with shaking (190 rpm). The supernatant fluid from culture was separated by centrifugation $\left(5,000 \times g, 4^{\circ} \mathrm{C}, 15 \mathrm{~min}\right)$ and subsequently lyophilized. Then, two-step liquid-liquid extraction was performed, similar to our previous methodology [27].

Briefly, the lyophilized sample was redissolved in water, extracted twice with ethyl acetate and dried under reduced pressure. The remaining aqueous phase was mixed with four equivalents of methanol and deep-frozen $\left(-80^{\circ} \mathrm{C}, 1 \mathrm{~h}\right)$. Precipitated proteins were removed by centrifugation $\left(14,000 \times g, 4{ }^{\circ} \mathrm{C}, 10 \mathrm{~min}\right)$, and the supernatant was transferred to a vial with the residue from the evaporated ethyl acetate fraction and concentrated under reduced pressure. The pooled extract was resuspended in 5\% liquid chromatography-mass spectrometry (LC-MS)-grade acetonitrile and injected onto an Acquity HSS T3 C18 analytical column $(1.8 \mu \mathrm{m}, 1.0 \times 150 \mathrm{~mm}$, Waters, Milford, MA, USA). Analytes were gradient-eluted with a $50 \mu \mathrm{L} / \mathrm{min}$ flow rate (A: $1 \%$ ACN with $0.1 \%$ formic acid in water, B: $95 \%$ ACN with $0.1 \%$ aqueous formic acid): $0 \mathrm{~min}, 2 \% ; 2 \mathrm{~min}, 2 \%$; $9 \mathrm{~min}, 60 \% ; 11.0 \mathrm{~min}, 99 \%$; $14 \mathrm{~min}$, $99 \% ; 14.5 \mathrm{~min}, 2 \%$; and $20 \mathrm{~min}, 2 \%$ of B.

To quantify metabolites from crude extracts, we performed high-performance liquid chromatography (HPLC)-MS on a Dionex UltiMate 3000 UHPLC system (Thermo Fisher Scientific, Waltham, MA, USA) connected to a SolariX 12T Fourier transform ion cyclotron resonance mass spectrometer (Bruker Daltonics, Billerica, MA, USA) in electrospray ionization (ESI) positive-ion mode. The two $\mathrm{CASI}^{\mathrm{TM}}$ (continuous accumulation of selected ions) windows were adjusted by a quadrupolar filter to 200-700 (low mass, LM) and 500-1500 (high mass, HM) Daltons. Qualitative and quantitative data processing was performed by our inhouse CycloBranch [40] version 2.0.8 and Bruker Data Analysis 5.0 software, respectively.

RHF and bis-imido-RHF were quantified in fermentation broths by the standard addition method. The standards were obtained from EMC Microcollections, GmbH (Tubingen, Germany). The limit of detection (LOD) and limit of quantitation (LOQ) were defined as the sum of the background average with 3 and 10 multiples of standard deviation, respectively. All samples were measured in triplicate.

\subsection{Molecular Identification and Human Sample Collection}

Template DNA was isolated from mycelium grown in yeast malt broth (Sigma-Aldrich, Ltd., St. Louis, MO, USA) for four days at $28^{\circ} \mathrm{C}$ with shaking (100 rpm). The high-purity polymerase chain reaction (PCR) template preparation kit (Roche Diagnostics, Mannheim, Germany) was used as follows: mycelium was suspended in $10 \mathrm{mM}$ EDTA buffer $(1 \mathrm{~mL})$, sonicated $3 \times 20 \mathrm{~s}$ within a 2 -min interval (5 W power, Microson ultrasonic disruptor, Labcaire) and centrifuged. For sample lysate, $200 \mu \mathrm{L}$ of lysis buffer containing $0.2 \mathrm{M}$ Tris- $\mathrm{HCl}$ (pH 7.5), $0.5 \mathrm{M} \mathrm{NaCl}, 0.01 \mathrm{M}$ EDTA, $1 \%$ SDS, and 10 $\mu \mathrm{L}$ of lyticase $(0.5 \mathrm{mg} / \mathrm{mL})$ was added to the mycelial pellet and incubated at $37^{\circ} \mathrm{C}$ for 30 min. The reaction was supplemented with $40 \mu \mathrm{L}$ of proteinase $\mathrm{K}$ solution and incubated at $68^{\circ} \mathrm{C}$ overnight. The purification further proceeded with the addition of $200 \mu \mathrm{L}$ of binding buffer. PCR was carried out to amplify the fungal DNA parts of the 18S rRNA, ITS1 and ITS2, 5.8 S, and $28 \mathrm{~S}$ gene regions with the primer set F1422/ITS7. PCR amplicons were purified with the Roche purification kit, sequenced with the PCR and internal primers ITS1F, ITS2, and ITS4, analyzed by Lasergene (DNASTAR Inc., Madison, WI, USA) and queried in the International Society of Human and Animal Mycology ITS reference DNA barcoding database.

The urine and serum were obtained from a patient with an invasive $R$. microsporus infection. In line with the EORTC/MSG 2019 (European Organization for Research and Treatment of Cancer and the 
Mycoses Study Group) [41] criteria, mucormycosis was proven by PCR and rDNA sequencing. The specimens were collected twice between 2019 and 2020 at the Faculty Hospital in Prague Motol, Czech Republic. The study adhered to the Declaration of Helsinki, 2013, Good Clinical Practice, and was approved by the Ethics Committee for Multi-Centric Clinical Trials of the Charles University Hospital Motol, Prague (EK-826/19).

\section{Results}

\subsection{HPLC Separation and Annotation of Rhizoferrin Analogs}

The initial separation attempts started with the application of a standard Waters Acquity HSS T3 $(1.0 \times 150 \mathrm{~mm}, 1.8 \mu \mathrm{m})$ column. The stationary phase revealed considerable adsorption of desferri-RHF. Injections exceeding $1 \mu \mathrm{g} / \mathrm{mL}$ became visible as an iron complex of $\mathrm{RHF}$ when $\mathrm{Fe}^{3+}$ ions from HPLC stainless steel tubing were trapped by RHF. The desolvation temperature and ion transfer optical parameters were optimized to reduce the in-source fragmentation.

R. microsporus cultivation under iron-limited conditions and D-glucose as a carbon source provided RHF and imido-RHF as two dominant products in the small molecule CASI LM window (Figure 1A). Five months of storage at room temperature, even in a dried lyophilized state, caused extensive RHF decomposition to the imido- and bis-imido-RHF forms (Figure 1B). The RHF trace was visible with a deteriorated peak shape of the protonated molecules at $\mathrm{m} / \mathrm{z} 437.140$ (Figure 1E). The citryl-RHF intermediate eluted at $2.36 \mathrm{~min}$ and was characterized by the accurate mass of the protonated molecule at $\mathrm{m} / \mathrm{z} 263.124$ (263.124 calculated for $\mathrm{C}_{10} \mathrm{H}_{18} \mathrm{~N}_{2} \mathrm{O}_{6}$ ).

For the first time, we report the production of glycosylated RHF analogs in directed biosynthesis (Figure 1G-I). Compared to their parent compounds (RHF and imido-RHF), both di- and tetra-Hex-RHFs had a mutually different and slightly lower affinity to the stationary phase. The positive-ion ESI mass spectra provided clusters of protonated and cationized species (data not shown). Ionic signals of the putative mono- and tri-Hex-RHFs coeluted with the corresponding di- and tetra-analogs. Although the formation of mono- and tri-Hex-RHFs cannot be excluded, at present, we conclude that the corresponding ionic species represent fragments rather than biosynthetic intermediates. On the other hand, di-Hex-imido-RHF was separated (Figure 1I).

The product ion mass spectra of the di- and tetra-Hex analogs revealed the consecutive losses of Hex units from the protonated molecules (Figure $1 \mathrm{~L}, \mathrm{M}$ ) and the intrinsic fragmentations in the aglycone RHF part (Figure 1J,K). The ion compositions derived from exact mass measurements (Supplementary section) do not contradict the fragmentation behavior indicated in Figure 1. CycloBranch provided the direct annotation of the components in the library search against the list of metabolites (Table 1).

\subsection{Quantitation of Rhizoferrins}

The fresh sample from the fermentation broth lyophilizate contained $345.3 \pm 13.5,1.2 \pm 0.03$, and $0.03 \pm 0.002 \mathrm{mg} / \mathrm{g}$ of RHF, imido-RHF, and bis-imido-RHF, respectively. The LOD and LOQ calculated from the bis-imido-RHF signal-to-noise ratios were 1.0 and $3.2 \mathrm{ng} / \mathrm{mL}$, respectively. The accurate LOD and LOQ for RHF could not be determined due to extreme sorption during HPLC separation. The complete standard addition procedure is described in the Supplementary section. We can only estimate that a minimum RHF concentration of $1 \mu \mathrm{g} / \mathrm{mL}$ is needed for RHF recovery from the HSS T3 column. This concentration is two to three orders of magnitude higher than that expected for the RHF concentration in clinical samples. 


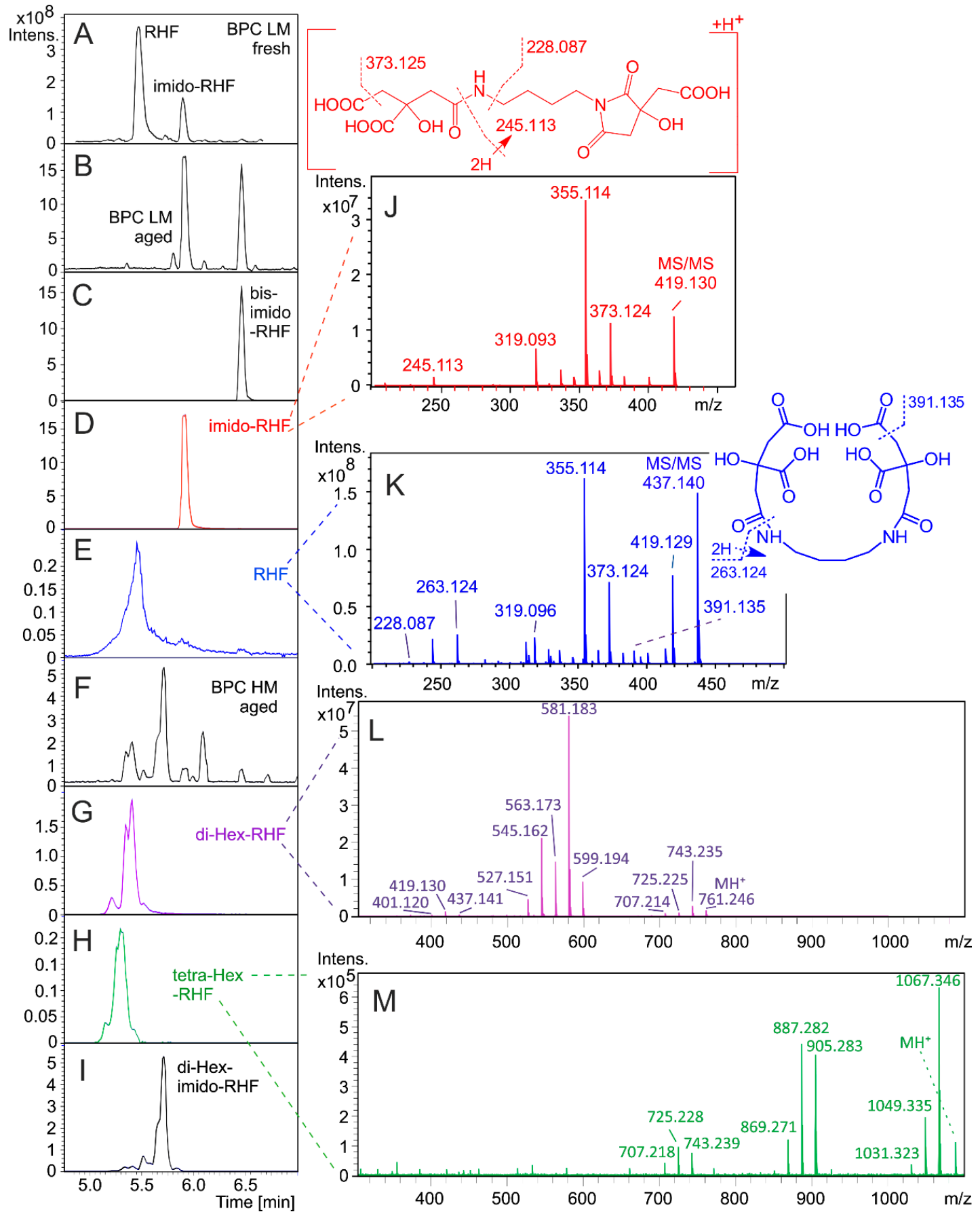

Figure 1. Chromatographic separation and tandem mass spectrometry of $R$. microsporus secondary metabolites. BPC: base peak chromatogram (CASI LM or HM windows), Hex stands for hexose. (A,B), BPC in the 200-700 Daltons mass range run on fresh or aged (5 months) lyophilizates; (C-E), reconstructed ion mass chromatograms corresponding to bis-imido-RHF, imido-RHF, and RHF, respectively (0.005 Dalton window). The BPC and selected ion chromatograms of di-Hex-RHF, tetra-Hex-RHF, and di-Hex-imido-RHF are shown in panels (F-I), respectively (all HM). Panels (J-M) refer to the product ion mass spectra (10 eV collisional energy) of imido-RHF, RHF, di-Hex-RHF, and tetra-Hex-RHF, respectively. The structure on the top indicates the intrinsic fragmentation in the RHF molecule. 


\section{Discussion}

Aging of the lyophilizate exhibited considerable RHF and imido-RHF instabilities (Figure 1B). Due to enzymatic processes in human serum or urine, the RHF stability in those matrices is expected to be even more compromised. Hence, bis-imido-RHF or its metabolic forms were one of the few R. microsporus biomarkers remaining in bodily fluids for targeted metabolomics.

RHF's glycosylation provides products that are more polar and possibly more enzymatically stable. We can only speculate whether RHF glycosylation may represent some benefit to the producer; e.g., biotransformation has been reported for detoxification of compounds. For example, $R$. microsporus converted zearalenone to its more soluble $4-\beta-D-$ glucopyranoside [42]. Of note, the presence of glucosyltransferases in the genus Rhizopus is not scarce, and these enzymes are used, e.g., in estrogen biotransformation [43].

RHF itself is an analytically difficult molecule for direct detection in patients with invasive mucormycoses, and its metabolic fate in the host body remains obscure. Our detection experiments with RHF analogs directly in human urine or serum samples have not yet been conclusive. The antifungal treatment likely stopped siderophore production before we could perform the actual sampling. Although RHF is the dominant product of R. microsporus cultivation under iron-restricted conditions, the RHF potential for zygomycete diagnostics needs to be demonstrated in the future with different sample preparation protocols, including chemical derivatization.

The mass spectrometer itself is sufficiently sensitive, as documented on urine analysis of the same patient, from which the Rhizopus isolate was originally obtained. The patient $(M, 67)$ suffered from pulmonary mucormycosis, confirmed by microscopy, cultivation and PCR. The first urinal sampling started three months after initiating Noxafil antifungal treatment (Figure 2). Posaconazole $\left(\mathrm{C}_{37} \mathrm{H}_{42} \mathrm{~N}_{8} \mathrm{O}_{4} \mathrm{~F}_{2}\right)$ is primarily metabolized via UDP glucuronosyltransferase [44]. In addition to the parent antifungal drug, we can directly monitor all its major metabolites, including hydroxyderivatives or glucuronides, in a single run.

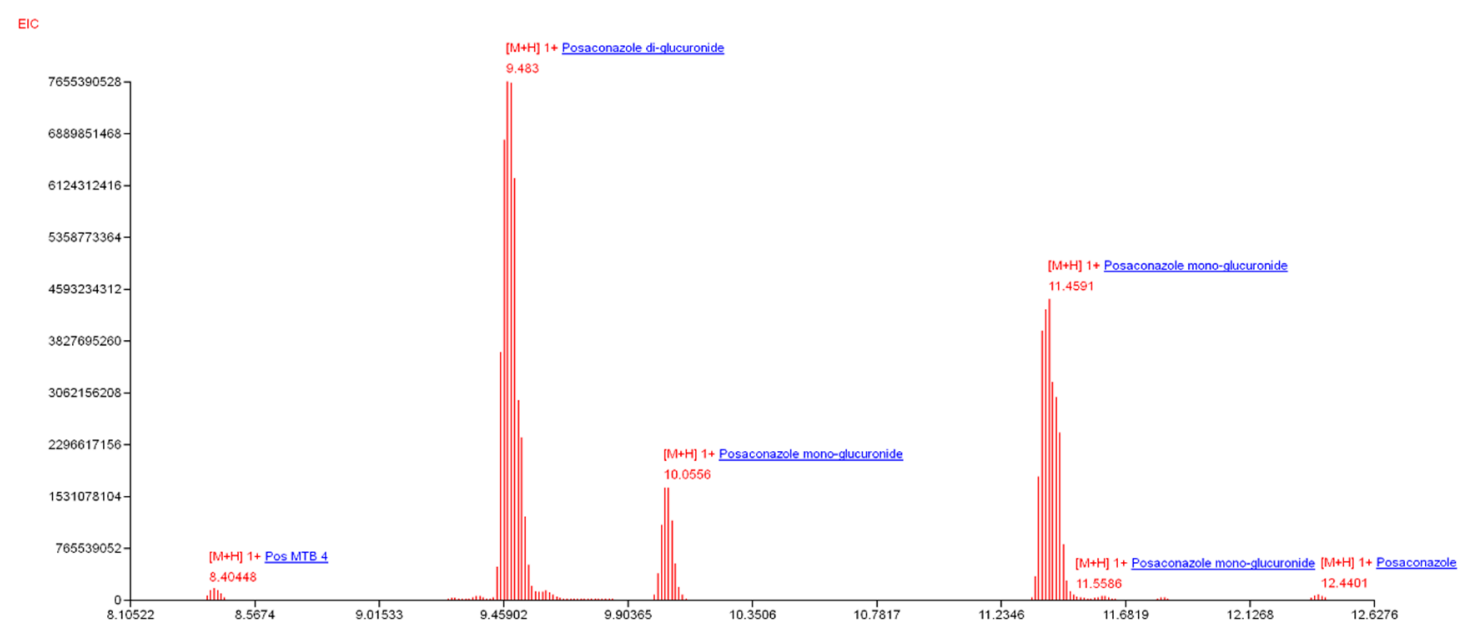

Figure 2. Annotation of posaconazole and its metabolites in the patient's urine by CycloBranch (15 ppm accuracy, $0.4 \%$ minimum relative intensity threshold, 1,000,000 minimum absolute intensity threshold, full pattern with a minimum of three isotope peaks in at least three consecutive scans). The CycloBranch internal mucormycotic database was amended with current antifungals and their metabolites [36].

Future studies are needed to determine the biotransformations of RHF in the host and to precisely reveal the chemical stability and protein binding of RHF. Patient specimen collection before the initiation of antifungal treatment is a prerequisite for successful detection of any iron-laden RHF analogs indicating mucoromycete proliferation in the host. This research is worth undertaking as it could provide noninvasive access to early biomarkers for a disease that provides blood cultures that 
are rarely positive, even when dissemination has occurred [45]. Our future attempts will be directed to RHF desoxy derivatives and chemical modification of rhizoferrin.

The comparative genomics approaches are also needed for the allocation of genes coding the putative glucosyltransferases. The whole-genome shotgun sequencing predicted glycosyltransferase/ glycogen phosphorylase genes, e.g., in $R$. microsporus ATCC strains 52,813, 11,559, 52,814, 62,417, one CBS-344.29 strain, and in R. delemar RA 99-880 (http://fungi.ensembl.org). By May 2020 no evidence on rhizoferrin, its glycosylated forms, or other analogs have been reported in the literature either in the patients' samples or in the animal models. We do not know whether the RHF is truly secreted in the human host at the invasive stage of the disease. Similarly, no information is available about RHF's possible renal secretion and protein binding. As siderophore secretion has been defined as one of the most important factors of virulence, including the RHF secretion [46], we hypothesize that the obstacles with RHF detection in the host rise rather from its high reactivity and instability. It is, therefore, our closest plan to set up an animal infection model with ${ }^{68} \mathrm{Ga}$-labeled RHF as a radiotracer.

Supplementary Materials: The following are available online at http://www.mdpi.com/2309-608X/6/2/89/s1, Supplementary Section: Standard addition, Exact tandem mass spectrometry.

Author Contributions: Mass spectrometry data collection, review, and editing, A.Š.; mass spectrometry data collection, review, and editing, R.H.P.; ethical and patient consent, clinical isolates, e-CRF, P.H.; ethical and patient consent, clinical isolates, e-CRF, R.D.; microbiology, review and editing, A.P.; fungal genetics, review and editing, H.M.; quantitation, review and editing, T.P.; conceptualization, methodology, data curation, formal analysis, writing-original draft preparation, revision and editing, funding acquisition, V.H. All authors have read and agreed to the published version of the manuscript.

Funding: This research was funded by the Ministry of Education, Youth and Sports of the Czech Republic, grant number LO1509, Czech Science Foundation, grant number 19-10907S, Motol University Hospital (research concept 64203) and the internal grant agency of Palacky University (IGA_PrF_2020_030).

Conflicts of Interest: The authors declare no conflict of interest.

\section{References}

1. Morin-Sardin, S.; Nodet, P.; Coton, E.; Jany, J.-L. Mucor: A Janus-faced fungal genus with human health impact and industrial applications. Fungal Biol. Rev. 2017, 31, 12-32. [CrossRef]

2. Voigt, K.; Wolf, T.; Ochsenreiter, K.; Nagy, G.; Kaerger, K.; Shelest, E.; Papp, T. Genetic and metabolic aspects of primary and secondary metabolism of the zygomycetes. In Biochemistry and Molecular Biology; Hoffmeister, D., Ed.; Springer International Publishing: Cham, Switzerland, 2016; pp. 361-385.

3. Müller, C.; Neugebauer, T.; Zill, P.; Lass-Flörl, C.; Bracher, F.; Binder, U. Sterol composition of clinically relevant mucorales and changes resulting from posaconazole treatment. Molecules 2018, 23, 1218. [CrossRef] [PubMed]

4. Gooday, G.W.; Carlile, M.J. The discovery of fungal sex hormones: III. Trisporic acid and its precursors. Mycologist 1997, 11, 126-130. [CrossRef]

5. Hollmann, M.; Razzazi-Fazeli, E.; Grajewski, J.; Twaruzek, M.; Sulyok, M.; Böhm, J. Detection of 3-nitropropionic acid and cytotoxicity in Mucor circinelloides. Mycotoxin Res. 2008, 24, 140-150. [CrossRef] [PubMed]

6. Jennessen, J.; Nielsen, K.F.; Houbraken, J.; Lyhne, E.K.; Schnürer, J.; Frisvad, J.C.; Samson, R.A. Secondary metabolite and mycotoxin production by the Rhizopus microsporus group. J. Agric. Food Chem. 2005, 53, 1833-1840. [CrossRef] [PubMed]

7. Partida-Martinez, L.P.; Flores de Looß, C.; Ishida, K.; Ishida, M.; Roth, M.; Buder, K.; Hertweck, C. Rhizonin, the first mycotoxin isolated from the zygomycota, is not a fungal metabolite but is produced by bacterial endosymbionts. Appl. Environ. Microbiol. 2007, 73, 793-797. [CrossRef]

8. Winkelmann, G. A search for glomuferrin: A potential siderophore of arbuscular mycorrhizal fungi of the genus Glomus. Biometals 2017, 30, 559-564. [CrossRef]

9. Carroll, C.S.; Grieve, C.L.; Murugathasan, I.; Bennet, A.J.; Czekster, C.M.; Lui, H.; Naismith, J.; Moore, M.M. The rhizoferrin biosynthetic gene in the fungal pathogen Rhizopus delemar is a novel member of the NIS gene family. Int. J. Biochem. Cell Biol. 2017, 89, 136-146. [CrossRef] 
10. Polaino, S.; Gonzalez-Delgado, J.A.; Arteaga, P.; Herrador, M.M.; Barrero, A.F.; Cerdá-Olmedo, E. Apocarotenoids in the sexual interaction of Phycomyces blakesleeanus. Org. Biomol. Chem. 2012, 10, 3002-3009. [CrossRef]

11. Lee, S.C.; Heitman, J. Sex in the Mucoralean fungi. Mycoses 2014, 57 (Suppl. 3), 18-24. [CrossRef]

12. Sutter, R.P.; Capage, D.A.; Harrison, T.L.; Keen, W.A. Trisporic acid biosynthesis in separate plus and minus cultures of Blakeslea trispora: Identification by Mucor assay of two mating-type-specific components. J. Bacteriol. 1973, 114, 1074-1082. [CrossRef] [PubMed]

13. Smith, M.J.; Shoolery, J.N.; Schwyn, B.; Holden, I.; Neilands, J.B. Rhizobactin, a structurally novel siderophore from Rhizobium meliloti. J. Am. Chem. Soc. 1985, 107, 1739-1743. [CrossRef]

14. Drechsel, H.; Tschierske, M.; Thieken, A.; Jung, G.; Zähner, H.; Winkelmann, G. The carboxylate type siderophore rhizoferrin and its analogs produced by directed fermentation. J. Ind. Microbiol. 1995, 14, 105-112. [CrossRef]

15. Haselwandter, K.; Haas, H.; Häninger, G.; Winkelmann, G. Siderophores in plant root tissue: Tagetes patula nana colonized by the arbuscular mycorrhizal fungus Gigaspora margarita. Biometals 2020. [CrossRef]

16. Gao, S.-S.; Li, X.-M.; Williams, K.; Proksch, P.; Ji, N.-Y.; Wang, B.-G. Rhizovarins A-F, indole-diterpenes from the mangrove-derived endophytic fungus Mucor irregularis QEN-189. J. Nat. Prod. 2016, 79, 2066-2074. [CrossRef]

17. Schwartze, V.U.; Winter, S.; Shelest, E.; Marcet-Houben, M.; Horn, F.; Wehner, S.; Linde, J.; Valiante, V.; Sammeth, M.; Riege, K.; et al. Gene expansion shapes genome architecture in the human pathogen Lichtheimia corymbifera: An evolutionary genomics analysis in the ancient terrestrial Mucorales (Mucoromycotina). PLoS Genet. 2014, 10, e1004496. [CrossRef]

18. Drechsel, H.; Metzger, J.; Freund, S.; Jung, G.; Boelaert, J.R.; Winkelmann, G. Rhizoferrin-A novel siderophore from the fungus Rhizopus microsporus var. rhizopodiformis. Biol. Met. 1991, 4, 238-243. [CrossRef]

19. Sullivan, J.T.; Jeffery, E.F.; Shannon, J.D.; Ramakrishnan, G. Characterization of the siderophore of Francisella tularensis and role of fslA in siderophore production. J. Bacteriol. 2006, 188, 3785-3795. [CrossRef]

20. Carroll, C.S.; Moore, M.M. Ironing out siderophore biosynthesis: A review of non-ribosomal peptide synthetase (NRPS)-independent siderophore synthetases. Crit. Rev. Biochem. Mol. Biol. 2018, 53, 356-381. [CrossRef]

21. Pluhacek, T.; Lemr, K.; Ghosh, D.; Milde, D.; Novak, J.; Havlicek, V. Characterization of microbial siderophores by mass spectrometry. Mass Spectrom. Rev. 2016, 35, 35-47. [CrossRef]

22. Hider, R.C.; Kong, X. Chemistry and biology of siderophores. Nat. Prod. Rep. 2010, 27, 637-657. [CrossRef]

23. Felsenfeld, A.J.; Rodriguez, M.; Coleman, M.; Ross, D.; Llach, F. Desferrioxamine therapy in hemodialysis patients with aluminum-associated bone disease. Kidney Int. 1989, 35, 1371-1378. [CrossRef] [PubMed]

24. Bonomo, R.A. Cefiderocol: A novel siderophore cephalosporin defeating carbapenem-resistant pathogens. Clin. Infect. Dis. 2019, 69, S519-S520. [CrossRef] [PubMed]

25. Dobias, R.; Havlicek, V. Microbial siderophores: Markers of infectious diseases. In Microbial and Natural Macromolecules: Synthesis and Applications; Das, S., Das, H.R., Eds.; Academic Press, Elsevier: Cambridge, MA, USA, 2020.

26. Hoenigl, M.; Orasch, T.; Faserl, K.; Prattes, J.; Loeffler, J.; Springer, J.; Gsaller, F.; Reischies, F.; Duettmann, W.; Raggam, R.B.; et al. Triacetylfusarinine C: A urine biomarker for diagnosis of invasive aspergillosis. J. Infect. 2019, 78, 150-157. [CrossRef] [PubMed]

27. Pluhacek, T.; Skriba, A.; Novak, J.; Luptakova, D.; Havlicek, V. Analysis of microbial siderophores by mass spectrometry. In Methods Molecular Biology; Bhattacharya, S.K., Ed.; Springer Nature: New York, NY, USA, 2019.

28. Devireddy, L.R.; Hart, D.O.; Goetz, D.H.; Green, M.R. A mammalian siderophore synthesized by an enzyme with a bacterial homolog involved in enterobactin production. Cell 2010, 141, 1006-1017. [CrossRef] [PubMed]

29. Bao, G.; Clifton, M.; Hoette, T.M.; Mori, K.; Deng, S.-X.; Qiu, A.; Viltard, M.; Williams, D.; Paragas, N.; Leete, T; et al. Iron traffics in circulation bound to a siderocalin (Ngal)-catechol complex. Nat. Chem. Biol. 2010, 6, 602-609. [CrossRef]

30. Münzinger, M.; Taraz, K.; Budzikiewicz, H.; Drechsel, H.; Heymann, P.; Winkelmann, G.; Meyer, J.-M. S, S-rhizoferrin (enantio-rhizoferrin)-a siderophore of Ralstonia (Pseudomonas) pickettii DSM 6297-the optical antipode of R, R-rhizoferrin isolated from fungi. Biometals 1999, 12, 189-193. [CrossRef] 
31. Burnside, D.M.; Wu, Y.; Shafaie, S.; Cianciotto, N.P. The Legionella pneumophila siderophore legiobactin is a polycarboxylate that is identical in structure to rhizoferrin. Infect. Immun. 2015, 83, 3937-3945. [CrossRef]

32. Kühn, S.; Braun, V.; Köster, W. Ferric rhizoferrin uptake into Morganella morganii: Characterization of genes involved in the uptake of a polyhydroxycarboxylate siderophore. J. Bacteriol. 1996, 178, 496-504. [CrossRef]

33. Matzanke, B.F.; Böhnke, R.; Möllmann, U.; Schünemann, V.; Schumann, G.; Trautwein, A.X.; Winkelmann, G. Transport and utilization of rhizoferrin bound iron in Mycobacterium smegmatis. Biometals 1999, 12, 315-321. [CrossRef]

34. Dadwal, S.S.; Kontoyiannis, D.P. Recent advances in the molecular diagnosis of mucormycosis. Expert Rev. Mol. Diagn. 2018, 18, 845-854. [CrossRef] [PubMed]

35. Reid, G.; Lynch, J.P.; Fishbein, M.C.; Clark, N.M. Mucormycosis. Semin Respir. Crit. Care Med. 2020, 41, 99-114. [CrossRef]

36. Houšt', J.; Spížek, J.; Havlíček, V. Antifungal drugs. Metabolites 2020, 10, 106. [CrossRef]

37. Larcher, G.; Dias, M.; Razafimandimby, B.; Bomal, D.; Bouchara, J.-P. Siderophore production by pathogenic mucorales and uptake of deferoxamine B. Mycopathologia 2013, 176, 319-328. [CrossRef] [PubMed]

38. Kousser, C.; Clark, C.; Sherrington, S.; Voelz, K.; Hall, R.A. Pseudomonas aeruginosa inhibits Rhizopus microsporus germination through sequestration of free environmental iron. Sci. Rep. 2019, 9. [CrossRef] [PubMed]

39. Boukhalfa, H.; Reilly, S.D.; Michalczyk, R.; Iyer, S.; Neu, M.P. Iron(III) coordination properties of a pyoverdin siderophore produced by Pseudomonas putida ATCC 33015. Inorg. Chem. 2006, 45, 5607-5616. [CrossRef] [PubMed]

40. Novák, J.; Škríba, A.; Havlíček, V. CycloBranch 2: Molecular formula annotations applied to imzML data sets in bimodal fusion and LC-MS data files. Anal. Chem. 2020, 92, 6844-6849. [CrossRef]

41. Donnelly, J.P.; Chen, S.C.; Kauffman, C.A.; Steinbach, W.J.; Baddley, J.W.; Verweij, P.E.; Clancy, C.J.; Wingard, J.R.; Lockhart, S.R.; Groll, A.H.; et al. Revision and update of the consensus definitions of invasive fungal disease from the European organization for research and treatment of cancer and the mycoses study group education and research consortium. Clin. Infect. Dis. 2019. [CrossRef]

42. Kamimura, H. Conversion of zearalenone to zearalenone glycoside by Rhizopus sp. Appl. Environ. Microbiol. 1986, 52, 515-519. [CrossRef]

43. Li, P.; Sun, C.; Wang, Y.; Wang, S.; Yan, C.; Deng, S.; Huo, X.; Feng, L.; Wang, C.; Tian, Y.; et al. Efficiently regioselective glucosylation of estrogen analogues mediated by fungus Rhizopus oryzae AS 3.2380. Catal. Commun. 2017, 97, 106-110. [CrossRef]

44. Li, Y.; Theuretzbacher, U.; Clancy, C.J.; Nguyen, M.H.; Derendorf, H. Pharmacokinetic/pharmacodynamic profile of posaconazole. Clin. Pharmacokinet. 2010, 49, 379-396. [CrossRef] [PubMed]

45. Hamilos, G.; Samonis, G.; Kontoyiannis, D.P. Pulmonary mucormycosis. Semin Respir. Crit. Care Med. 2011, 32, 693-702. [CrossRef] [PubMed]

46. Ramakrishnan, G. Iron and virulence in Francisella tularensis. Front. Cell. Infect. Microbiol. 2017, 7. [CrossRef] [PubMed]

(C) 2020 by the authors. Licensee MDPI, Basel, Switzerland. This article is an open access article distributed under the terms and conditions of the Creative Commons Attribution (CC BY) license (http://creativecommons.org/licenses/by/4.0/). 